\title{
La fuerza del derecho: sanciones, coerción y coacción
}

\author{
Sanctions, Coercion and Compulsion
}

\author{
Fabio Enrique Pulido OrTiZ \\ Departamento de Teoría Jurídica y de la Constitución \\ Universidad de La Sabana (Colombia). \\ https://orcid.org/0000-0002-1100-9962 \\ fabio.pulido@unisabana.edu.co
}

\begin{abstract}
Resumen: Este artículo se propone analizar las nociones de sanción, coerción y coacción, identificando sus conexiones y diferencias conceptuales. El autor defiende tres tesis: en primer lugar, se afirma que las sanciones jurídicas son las consecuencias contingentes definidas por las reglas jurídicas para motivar a los individuos a actuar de conformidad con los deberes legales. Segundo, se argumenta que la coerción corresponde a las razones para la acción que son generados en los individuos por la probabilidad de la aplicación de las consecuencias (negativas o positivas) definidas en las sanciones. Por último, se distinguen tres nociones asociadas a la coacción: 1) la coacción como aplicación de sanciones (señalando que no toda sanción implica necesariamente uso de la fuerza); 2) la coacción como ejecución institucional de derechos y deberes (subrayando que este tipo de coacción no es lo mismo que aplicar sanciones) y 3) la coacción como uso de la fuerza (resaltando que este sentido de coacción es conceptualmente independiente de la aplicación de sanciones y de la ejecución institucional de derechos y deberes).
\end{abstract}

Palabras clave: Teoría del derecho, normatividad del derecho, razón práctica, sanciones, coacción.

\begin{abstract}
This paper analyses the meaning and conceptual connections between sanction, coercion and the use of force. The author defends three theses. First, sanctions are contingent consequences defined by legal rules to motivate people to act in conformity to legal duties. Second, it is argued that coercion involves reasons for actions generated by the deliberator, who calculates the likelihood of the consequences (positive or negative) established in the sanctions. Third, there are three notions associated to legal compulsion: a) the application of sanctions (highlighting that every legal application of sanction is done using force); b) the institutional enforcement of legal rights and duties (in which case, the use of force is independent of the application of sanctions, and not every institutional enforcement takes place through use of physical force); and finally, c) the generic legal use of force that, in fact, is conceptually independent of both legal sanction and the enforcement of rights and duties
\end{abstract}

Keywords: legal theory, normativity of law, practical reason, sanctions, coercion.

* Este artículo forma parte de los resultados del proyecto de investigación DERMSC-1-2018 financiado por la Dirección General de Investigaciones de la Universidad de La Sabana. El autor agradece a los profesores Pilar Zambrano, Paula Gaido, Andrej Kristan, Juan Cianciardo, Luciano Laise, Pablo Rivas Robledo y Raquel Sarria por sus comentarios a versiones anteriores de este artículo. También agradece a los participantes del seminario «coerción» organizado por el departamento de teoría jurídica y de la constitución de la Universidad de La Sabana, en especial a Sergio Morales, Natalia Ariza, Carolina Benjumea, y María Camila Osorio. 


\section{INTRODUCCIÓN}

Cuando se indaga acerca de la diferencia entre el derecho y otros tipo de ordenamientos normativos (v. gr. la moral), una de las respuestas comunes consiste señalar el carácter coercitivo de los ordenamientos jurídicos como un elemento distintivo ${ }^{1}$. No obstante, los filósofos del derecho no han logrado un acuerdo acerca de este asunto. Unos sostienen que la coerción es una propiedad contingente del derecho y que cumple un papel auxiliar en el funcionamiento de las normas jurídicas ${ }^{2}$. Otros piensan que la coerción se constituye en una propiedad necesaria para la existencia de las normas jurídicas o, en todo caso, de la forma como el derecho regula la conducta de los individuos ${ }^{3}$.

La investigación sobre la relación entre coerción y derecho se ha revitalizado en los últimos años ${ }^{4}$. Recientemente Schauer ha defendido que la fuerza

1 Dworkin, por ejemplo, piensa que una característica distintiva y fundamental del derecho es guiar y limitar el uso de la fuerza. Incluso -según Dworkin- las distintas discusiones en la teoría jurídica han girado en torno a la adecuada explicación y justificación de la conexión entre derecho y coerción. Dworkin, R., Law's Empire, Harvard University Press, Cambridge, 1986, pp. 93-96.

2 RAz, J., Practical Reason and Norms, Oxford University Press, Oxford, 1990, pp. 156-162; HaRT, H. L. A., The concept of law, 2a. ed., P. Bulloch y J. Raz, eds., Clarendon Press, Oxford, 1994, pp. 27-38.

3 Bobbio explica que entre los autores que defienden el carácter coercitivo del derecho deben diferenciarse dos posiciones: la primera afirma que la coerción es un elemento necesario de las normas jurídicas y la segunda que la coerción es el objeto del derecho, en el sentido que «el Derecho es un conjunto de normas que regulan el uso de la fuerza coactiva» (BoBBIO, N., El positivismo jurídico, Debate, Madrid, 1993, p. 165). La primera posición es sostenida, por ejemplo, por Austin (Austin, J., The province of jurisprudence determined, Cambridge University Press, Oxford, 1995, pp. 18-37), Holmes (Holmes, O.W., «The Path of the Law», Harvard Law Review, 10 [1897], pp. 457-478) y Kelsen (Kelsen, General Theory of Law and State, Harvard University Press, Cambridge Massachusetts, 1945, pp. 18-20, 60-61 e ID., Teoría Pura del Derecho, 14a. ed., trad. R. Vernengo, Porrúa, México, 2005, pp. 63, 129-130; 153-157). La segunda posición es sostenida por Dworkin (DwORKIN, R., Law's Empire, Harvard University Press, Cambridge, 1986, pp. 93-96) y también por Kelsen (KelSEN, H., «The Law as a Specific Social Technique», University of Chicago Law Review, 9 [1941], pp. 75-97). Otros autores, rechazan estas tesis, pero consideran que la coerción es un elemento característico del funcionamiento del derecho en la regulación de la acción de los individuos. Vease FINNIS, J., Natural law and natural rights, 2." ed., Oxford University Press, Oxford, 2011, pp. 260-254 y LAMOND, G., «Coercion and the Nature of Law», Legal Theory, 7 (2001), pp. 35-57).

4 El estudio de la relación entre derecho y coerción fue uno de los temes centrales el Congreso Mundial de la Asociación Internacional de Filosofía del Derecho y Filosofía Social (IVR) realizado en Washington (https://ivronlineblog.files.wordpress.com/2015/07/ivr-2015-worldcongress-program.pdf). El volumen 7 (3) de Jurisprudence. An International Journal of Legal and Political Thought estuvo dedicado a ese mismo tema.) 
y la coerción (force and coercion) son elementos omnipresentes en los ordenamientos jurídicos 5 . Para él, y a diferencia de fenómenos normativos (como la moral o la etiqueta), una característica distintiva del derecho es que dispone de sanciones (sanctions) para los casos de incumplimiento de sus normas y que esas sanciones forman parte principal de las razones por las cuales los individuos las obedecen ${ }^{6}$.

Schauer agrega que es paradigmático del derecho el empleo de diferentes medios coercitivos para compeler a los individuos sobre el cumplimiento de sus normas. En particular, la operación del derecho depende de que el incumplimiento de sus normas tenga como consecuencia la imposición de consecuencias dolorosas o costosas por lo que un derecho sin fuerza coercitiva no tiene una genuina capacidad de exigir acciones ${ }^{7}$. Concluye que de la observación de los ordenamientos jurídicos actuales (y de la forma como los individuos siguen las normas jurídicas) se evidencia la fuerza del derecho depende de la centralidad y ubicuidad de la coerción ${ }^{8}$.

Ahora bien, en el análisis de la relación entre derecho y coerción subyacen dos cuestiones. De acuerdo con la primera, es necesario indagar en qué sentido el derecho puede ser considerado un fenómeno coercitivo, es decir si alguna de sus propiedad es (o de pende de la) coerción. De acuerdo con la segunda, debe analizarse el concepto coerción ofreciendo una explicación de sus elementos característicos y su funcionamiento en el derecho ${ }^{9}$. La explicación de la coerción resulta, desde luego, fundamental. Existe una prioridad metodológica de la segunda cuestión sobre la primera en tanto no es posible concluir si el derecho es coercitivo si, previamente, no se comprende el concepto de coerción. Por esta razón, Schauer se vio en la necesidad de conceptualizar la coerción.

En la explicación de Schauer, la coerción incluye un amplio abanico de figuras dispuestas por el ordenamiento jurídico para lograr el cumplimiento de sus exigencias. Sostiene que la coerción incluye la amenaza de un castigo,

\footnotetext{
SCHAuer, F., The Force of the Law, Harvard University Press, Cambridge, 2015, p. ix.

Ibid., pp. 1-8; 55-56.

Ibid., pp. 1-10.

Ibid., pp. 154-168.

9 Debe subrayarse que la mayoría de las discusiones filosóficas contemporáneas sobre el asunto han girado en torno a la primera de las cuestiones señaladas. Véase HART, H. L. A., The concept of law, op. cit., pp. 27-38. RaZ, J., Practical Reason and Norms, op. cit., pp. 154-162. YanKaH, E., «The Force of Law: The Role of Coercion in Legal Norms», University of Richmond Law Review, 42 (2008), pp. 1195-1256; y LAMOND, G., Coercion and the Nature of Law, op. cit., pp. 35-57.
} 
pero también la imposición directa de comportamientos. Agrega que la fuerza del derecho no se reduce a la amenaza de castigos puesto que las prácticas jurídicas pueden incluir incentivos positivos (v. gr. premios) ${ }^{10}$. En el marco de esta caracterización, Schauer diferencia entre las nociones de sanción (sanctions), coerción (coerción) y coacción (compulsion). Según él, las sanciones se refiere a lo que el derecho impone a los individuos que no obedecen sus normas. La coerción, por su parte, es la motivación que puede generar el derecho en los individuos de realizar conductas que de otra forma no estarían dispuestos a realizar. La coacción, por último, ocurre cuando la fuerza coercitiva (la afectación en la motivación) realmente impacta en el comportamiento de los individuos ${ }^{11}$.

No obstante, existen dos problemas en la conceptualización de Schauer ${ }^{12}$. En primer lugar, Schauer busca demostrar que el derecho es característicamente coercitivo. Y es justamente por ello que recurre a un concepto amplio e impreciso de coerción: toda medida que implique la imposición de conductas. Este concepto -por vaguedad- no logra captar las diferencias, particularidades y conexiones de los diferentes fenómenos que designa con esos términos. En efecto, no pueden reducirse al mismo marco conceptual figuras jurídicas tan distintas como las amenazas de una sanción penal, las barreras que impiden el paso a una propiedad privada o las medidas preventivas para proteger a un ciudadano. Es cierto que todas esas figuras jurídicas son (en diferentes sentidos) formas de imposición de conductas. Pero por son justamente las diferencias y particularidades de cada una de ellas las que se Schauer no logra explicar. En segundo lugar, Schauer emplea su vago concepto de coerción para concluir que el derecho es coercitivo. Apela a diferentes ejemplos con los que espera mostrar el carácter coercitivo del

10 SCHAUER, F., The Force of the Law, op. cit., p. 7.

11 En sus palabras: «sanctions are what law imposes in the event of noncompliance with legal mandates... that law is coercive to the extent that its sanctions provide motivations for people, because of the law, to do something other than what they would have done absent the law; and that law can be said to exercise compulsion when its coercive force actually does induce the aforesaid shift in behavior» (SCHAUER, F., The Force of the Law, op. cit., p. 129).

12 Schauer no desarrolla en estricto sentido una empresa filosófica. Como lo explica Massini-Correas, ese libro no es en estricto sentido filosófico sino sociológico o pisco-psicológico pues se enfoca en «las motivaciones de la conducta jurídica y al impacto social de las diferentes formas de la coacción», además que «su principal referencia bibliográfica consiste en una serie de estudios de carácter empírico acerca del uso de la fuerza por el aparato estatal y de su repercusión en la vida social y jurídica». MASsINI-CorreAs, C., «The Force of Law», Persona y Derecho, 78 (2018), p. 351. 
derecho: las amenazas penales, la pérdida de privilegios legales, los premios, la vergüenza, la capacidad de expulsar de asociales o comunidades, la responsabilidad contractual y extracontractual, etc. El problema es que, al basarse en una conceptualización tan amplia, vaga y poco precisa de coerción, resulta dudoso derivar de allí las condiciones que sirvan para concluir que las prácticas jurídicas son paradigmáticamente coercitivas.

La falta de claridad al respecto genera -por lo menos- las siguientes inquietudes: ¿Qué significa que las sanciones son motivaciones para la conducta de los individuos? O, en otras palabras, ¿Qué tipo de motivaciones están involucradas en el funcionamiento de las sanciones? ¿Qué relaciones y diferencias existen entre las sanciones, la coerción y la coacción? ¿Puede una sanción ser coercitiva aun cuando no logre ser coactiva? ¿Puede una norma jurídica contemplar sanciones sin autorizar el uso de la fuerza? ¿Cuáles son las relaciones entre las sanciones, la coerción y la coacción con la existencia de deberes jurídico? ¿Es necesario el empleo de la fuerza para caracterizar una norma como coercitiva? ¿Es el empleo de la fuerza una característica de la coacción jurídica?

Una de las causas del problema radica justamente en la imprecisión respecto de los conceptos de sanción, coerción y coacción. Teniendo en mente esta cuestión, este artículo se propone analizar esos conceptos identificando sus características, conexiones y diferencias. En la primera parte, se examina el concepto de sanción jurídica. Luego se estudia el concepto de coerción, su funcionamiento en el razonamiento práctico. Finalmente, se estudiaran las distintas formas en que las actividades de las autoridades jurídicas pueden ser consideradas coactivas. A partir de lo anterior se afirma, primero, que las sanciones jurídicas son las consecuencias contingentes definidas por las reglas jurídicas para motivar a los individuos a actuar de conformidad con los deberes legales. Segundo, se argumenta que la coerción corresponde a las razones para la acción que son generados en los individuos por la probabilidad de la aplicación de las consecuencias (negativas o positivas) definidas en las sanciones. Por último, se distinguen tres nociones asociadas a la coacción: 1) La coacción como aplicación de sanciones (señalando que no toda sanción implica necesariamente uso de la fuerza); 2) la coacción como ejecución institucional de derechos y deberes (subrayando que este tipo de coacción no es lo mismo que aplicar sanciones) y 3) la coacción como uso de la fuerza (resaltando que este sentido de coacción es conceptualmente independiente de la aplicación de sanciones y de la ejecución institucional de derechos y deberes). 


\section{LAS SANCIONES JURÍDICAS}

Para iniciar la explicación, imaginemos la siguiente situación: una ley para la protección de la salud de las personas por los efectos del consumo de tabaco establece que «está prohibido fumar en lugares públicos no autorizados y quien incumpla esta prohibición será multado hasta con 60 días de salarios mínimos legales». En este ejemplo, es sencillo distinguir entre a) el deber creado en la ley (i.e la prohibición de fumar) y b) la sanción (i.e la multa).

A partir de esta distinción puede entenderse la diferencia planteada por Kelsen entre motivación directa e indirecta de la conducta. En la primera, es el deber el que motiva directamente a actuar de conformidad con las normas. En la segunda, el sistema normativo atribuye ventajas (sanciones positivas) a quienes actúan conforme a los deberes, o desventajas (sanciones negativas) a quienes los incumplen ${ }^{13}$. Los sistemas normativos que recurren a la motivación indirecta pueden, o bien encargarse ellos mismos de las sanciones (i.e sanciones organizadas), o recurrir a la sanciones que espontáneamente surjan en la comunidad por el incumplimiento (sanciones espontaneas) ${ }^{14}$.

De acuerdo con lo anterior, las sanciones se refieren a la atribución de ventajas a la observancia o desventajas a la inobservancia, establecidas por un sistema normativo como mecanismo para motivar a los individuos para actuar conforme a los deberes. No obstante, por razones de conveniencia y eficacia, los sistemas con sanciones organizadas (como los sistemas jurídicos) recurren comúnmente a la definición de sanciones negativas. Las desventajas definidas en las sanciones negativas corresponden a la imposición de un mal, entendido como la privación de bienes (v. gr. la vida, la libertad, la propiedad etc.) de los individuos que no cumplen con sus deberes. Y, según Kelsen, estas sanciones son coactivas toda vez que la privación del bien se realiza en contra de la voluntad de los individuos (más adelante se mostrará que no es cierto que toda aplicación de sanciones sea coactiva) ${ }^{15}$. Así, Kelsen subraya que el derecho es coercitivo en tanto es fundamentalmente una técnica social de motivar conductas a través de las sanciones dispuestas por el orden jurídico. Una sanción

13 Kelsen, H., «The Law as a Specific...», op. cit., p. 75.

14 Ibid., 76.

15 En sus palabras «The evil applied to the violator of the order when the sanction is socially organized, consists in a deprivation of possessions-life, health, freedom, or property. As the possessions are taken from him against his will, this sanction has the character of a measure of coercion», Kelsen, H., «The Law as a Specific...», op. cit., p. 78. 
depende de un acto de coacción (i.e, según Kelsen, la privación forzada de un bien) que es realizado por un sujeto determinado y dirigido por el ordenamiento jurídico e impuesto en contra del individuo responsable de la conducta contraria al orden ${ }^{16}$. Por lo tanto, según Kelsen, lo que diferencia a las normas jurídicas de -por ejemplo- las morales, es que existen medidas coercitivas previstas y organizadas por el sistema jurídico para los casos de incumplimiento ${ }^{17}$. $\mathrm{Al}$ planteamiento de Kelsen es posible formularle tres objeciones.

En primer lugar, y siguiendo en este punto la conocida critica de Hart, la noción de sanciones no es adecuada para explicar el funcionamiento del derecho en sus aspectos fundamentales. Una de las características más importantes del derecho es que no se limita a prescribir determinados cursos de acción, sino que posibilita la realización de determinados actos (públicos y privados) mediante la definición de potestades jurídicas (la potestad de hacer leyes, actos administrativos, contratos, testamentos etc.). En este escenario, resulta incorrecto pensar que si un determinado acto no logra cumplir las condiciones de la regla que define la potestad entonces los individuos están incumpliendo el derecho y, por tanto están siendo sancionados. Por ejemplo, la mayoría de normas civiles establecen una edad mínima como condición necesaria para contratar. Si se da el caso de un pequeño niño que pretendía vender uno de sus bienes, lo que ocurre en realidad es que su acto es nulo (invalido o inexistente), pero no podemos decir que el niño violo las prescripciones del derecho y que el sistema jurídico lo está castigando ${ }^{18}$.

$16 \mathrm{Ibid}$., p. 80. Por lo tanto, la coerción, para Kelsen, se refiere a la privación de bienes. Por esta razón piensa que en el derecho subyace la tensión de que su instrumento principal (el acto coercitivo) es del mismo tipo de los actos que pretende evitar. Los ordenamientos jurídicos pretenden evitar que los individuos atenten en contra de los bienes de los otros individuos. Pero para ello, el derecho recurre a las sanciones, esto es a la privación de bienes de los infractores: se emplea la fuerza para evitar el uso privado de la fuerza. Según Kelsen, esa tensión se desvanece una vez se comprende que el derecho y la fuerza no son conceptualmente contradictorios. Para él, la finalidad del derecho no es otra que la organización de la fuerza, estableciendo las condiciones que posibilitan a determinados sujetos a emplear la fuerza para restablecer el orden. KELSEN, H., «The Law as a Specific...», op. cit., pp. 78-81.

17 Kelsen piensa que el derecho es una técnica social que consiste en hacer que los individuos se abstengan de interferir en los intereses de los demás. En los casos de interferencia, el derecho reacciona mediante una interferencia en los intereses del individuo que acta en contra de lo prescrito en el orden: la interferencia por la fuerza en la esfera de los intereses del individuo infractor, es decir la medida coercitiva, es la sanción. Ibid., pp. 75-97.

18 Hart planeta esta cuestión en estos términos: The power thus conferred on individuals to mould their legal relations with others by contracts, wills, marriages, etc. is one of the great contributions of law to social life; and it is a feature of law obscured by representing all law as a matter of orders backed by threats... We may or may not 'comply' in making our will with the provision of 
En segundo lugar, la tesis de Kelsen no logra explicar cómo se relacionan las sanciones con la motivación de los individuos. Kelsen se limita a estipular que las sanciones motivan como consecuencia de su poder coercitivo (es decir, a su imposición en contra de la voluntad de los individuos). Pero ¿Cómo puede ocurrir esto? ¿Qué es lo que lleva a los individuos a actuar? No puede ser que los individuos actúen como consecuencia de la coacción pues -en los términos de Kelsen- en este evento el resultado es independiente de la voluntad del individuo (es la imposición de un estado de cosas). En otras palabras, Kelsen piensa que las sanciones dependen de medidas coactivas (esto es de actuaciones forzadas en contra de la voluntad de los individuos infractores) pero no explica cómo pueden las sanciones llevar a que los individuos actúen.

En tercer lugar, al desarrollar su concepción del derecho como un orden coercitivo, Kelsen piensa que existe una conexión conceptual entre a) la existencia de normas jurídicas, b) las medidas que el sistema jurídico dispone para asegurar su cumplimiento, c) la coerción y d) el uso de la fuerza. En otras palabras, cree que existe una conexión conceptual entre las normas jurídicas, las sanciones, la coerción y el uso de la fuerza. Para él, por ejemplo, el uso de la fuerza es una condición necesaria para que el derecho pueda disponer de consecuencias jurídicas en los casos de incumplimiento de las normas. Piensa, asimismo, que la aplicación de la ley es necesariamente la aplicación de una sanción. Y sostiene que lo especifico del derecho es la existencia de medidas coactivas como técnica de motivación para que lo individuos actúen conforme al orden. Sostiene también que afirmar la existencia de deber jurídico es lo mismo que sostener que la conducta contaría está amenazada con una sanción $^{19}$. Lo cierto es que, aun cuando se admita -en gracia de discusión- que una característica necesaria del derecho es la organización del uso de la fuerza, ello no es suficiente para mostrar que todas las sanciones dependen del uso

\footnotetext{
s. $g$ of the Wills Act, 1837, as to the number of witnesses. If we do not comply the document we have made will not be a 'valid' will creating rights and duties; it will be a 'nullity' without legal 'force' or 'effect'. But, though it is a nullity our failure to comply with the statutory provision is not a 'breach' or a 'violation' of any obligation or duty nor an 'offence' and it would be confusing to think of it in such terms. (HART, H. L. A., The concept of law, op. cit., p. 28)

19 Para Kelsen, el legislador establece en términos abstractos la relación entre una conducta y la sanción de forma tal que la aplicación de las normas consiste en determinar para un caso específico si se dan las condiciones concretas para sancionar. De tal forma, toda decisión judicial (en tanto acto paradigmático de aplicación del derecho) es en definitiva la determinación de una sanción individual. Kelsen, H., «The Law as a Specific...», op. cit., p. 89; ID., Teoría Pura del Derecho, op. cit., 246-258.
} 
de la fuerza (piénsese a manera de ejemplo en una sanción cuyo contenido es la pérdida de una potestad jurídica), ni mucho menos que toda aplicación del derecho es una sanción (si el juez ordena a $\mathrm{X}$ que le restituya el bien a $\mathrm{Y}$, en tanto es $\mathrm{Y}$ el propietario, no puede afirmarse que el juez esta sancionando a $\mathrm{X}$ privándolo de un bien de su propiedad).

En estos términos, la argumentación de Kelsen incurre en el mismo error de Schauer, esto es, recurrir a unos conceptos equívocos de sanción y coacción. Kelsen no logró precisar adecuadamente el contenido específico del concepto de sanción, ni logró precisar sus relaciones y diferencias con las nociones coerción, coacción y uso de la fuerza. Por ello, en las siguientes líneas se analizará el concepto de sanción jurídica y, en particular, la relación entre las sanciones y los deberes jurídicos. Para abordar esta se desarrollarán tres características: 2.1) la existencia de normas jurídicas no implica la existencia de sanciones; 2.2) el carácter reglado de la creación y aplicación de sanciones; y 2.3) las sanciones pretender se fuente de motivos para la acción. Una vez precisadas estas características, se podrán explicar las conexiones entre los conceptos de sanción, coerción y coacción (apartados 3 y 4).

\section{La existencia de normas jurídica no implica la existencia de sanciones}

En el ejemplo de la ley para la protección de la salud de las personas por los efectos del consumo de tabaco, observamos que es posible diferenciar dos cuestiones. Por un lado existe un deber legal (la prohibición de fumar), y por el otro existe una sanción ante el incumplimiento de ese deber jurídico (la multa). Kelsen piensa que existe una equivalencia entre afirmar que existe una norma jurídica y la sanción (el que fume será multado) ${ }^{20}$. Según él -como vimos- una característica distintiva de las normas jurídicas es el carácter coercitivo de los deberes jurídicos (i.e de los deberes creados por normas jurídicas) ${ }^{21}$.

20 ID., General Theory of Law and State, op. cit., pp. 18-20, 60-61; e ID., Teoría Pura del Derecho, op. cit., pp. 63, 129-130; 153-157.

21 En relación con la coerción es posible diferenciar dos tesis: (1) que es el medio a través del cual se hacen efectivas las normas jurídicas y (2) que la coerción es el objeto del derecho. Kelsen se ocupa de defender las dos tesis. Por un lado, sostiene que una norma jurídica no puede ser calificada como tal si no existe una sanción para los casos de incumplimiento y, además, que hace parte de la naturaleza del derecho regular la fuerza coactiva. A pesar de las relaciones que en efecto existen entre estas tesis, una de las conclusiones que arrojara el presente trabajo es que son tesis conceptualmente independientes. Es decir, al mostrarse que no existe una conexión conceptual 
El problema de esta conceptualización es que, en primer lugar, no es cierto que exista una conexión conceptual entre los deberes jurídicos y las sanciones; y en segundo lugar, la noción de sanciones no logra explicar las diferentes reglas que operan en los ordenamientos jurídicos.

Los ordenamientos jurídicos están conformados por dos tipos de normas: las normas prescriptivas y las normas secundarias. Las normas primarias son aquellas que exigen la realización (o no realización) de determinados tipos de acciones. Estas reglas se caracterizan por contener los siguientes elementos: el contenido de la regla, esto es una descripción de la clase de acciones humanas regulada por la norma jurídica. El carácter o calificación deóntica de la acción regulada, a saber la clasificación de la acción definida como obligatoria o prohibida. Y los sujetos vinculados, es decir los destinatarios de la acción exigida (en otras palabras la definición de los individuos que deben realizar la conducta exigida, prohibida o facultada por la norma). La estructura de estas normas puede ser sintetizada así: el sujeto $S$ debe realizar la acción $C^{22}$.

Las normas secundarias, por otro lado, son aquellas normas de los ordenamientos jurídicos cuya función es definir cómo identificar, crear, modificar, derogar o aplicar otras reglas ${ }^{23}$. En particular, es característico de los ordenamientos jurídicos que, con independencia de la exigencia de determinadas conductas, defina reglas que confieren competencias a las autoridades públicas $\mathrm{y}$ a los particulares para realizar determinados actos normativos ${ }^{24}$. Estas reglas

ente sanciones y coacción debe concluirse que aun cuando se admita que la coacción hace parte de la naturaleza del derecho, ello no implica que la naturaleza de sus normas sea sancionatoria.

22 Es oportuno hacer dos precisiones. En primer lugar, la idea básica que subyace en esta explicación es que os sistemas jurídicos no se pueden reducir a un tipo específico de normas (como pensaba Kelsen). Por el contrario, la existencia de normas que constituyen o posibilitan determinados actos (contratar, legislar, juzgar, derogar etc.) es tan fundamental para el derecho como la exigencia e conductas. Esta diferencia fue defendida, entre otros, por HART, H. L. A., The concept of law, op. cit.; y VON Wright, Norm and Action. A Logical Inquiry. Routledge \& Kegan Paul, London, 1963. En segundo lugar, teniendo en cuenta los límites de la investigación, he dejado de lado la explicación de la diferencia entre normas y reglas.

23 HaRT, H. L. A., The concept of law, op. cit., 79-89.

24 Alrededor de la explicación de las reglas secundarias existen diferentes problemáticas que no puedo desarrollar en este trabajo. En todo caso, sobre lo que no parce existir discusión es que las reglas de competencia (o reglas que confieren poderes) son un elemento necesario en el funcionamiento de cualquier ordenamiento jurídico y que, en efecto, la naturaleza de estas normas es suficientemente distinta a las normas que exigen conductas respaldas por sanciones como para pretender desarrollar una teoría de las normas jurídicas basada en la coerción. Sobre el particular véase HarT, H. L. A., The concept of law, op. cit.; y FERRER, J., Las normas de competencia. Un aspecto de la dinámica jurídica, Centro de Estudios Políticos y Constitucionales Madrid, 2000. 
están conformadas por a) el sujeto (público o privado) a quien se le otorga la potestad o competencia, b) el procedimiento y las formas mediante las cuales se ejerce la competencia y c) el tipo de actos que pueden ser generados a través del ejercicio de la potestad definida. Estructuralmente, estas reglas se pueden presentar de la siguiente manera: El sujeto $S$, mediante el procedimiento $P$, es competente para generar los actos normativos $N$.

En este orden de ideas, los ordenamientos jurídicos a través de sus normas prescriptivas exigen diferentes conductas (i.e establecen o reconocen deberes). Ahora bien, para ilustrar la relación entre las reglas prescriptivas las sanciones retomemos el ejemplo de la ley anti-tabaco. Esta ley, como se dijo, establece que «está prohibido fumar en lugares públicos no autorizados» y que «quien incumpla esta prohibición será multado hasta con 60 días de salarios mínimos legales». En esta disposición jurídica existen dos elementos claramente diferenciables:

(1) La existencia de un deber jurídico: no fumar

(2) La existencia de una sanción ante el incumplimiento de dicho deber: la multa.

A diferencia de lo que pensó Kelsen ${ }^{25}$, existe una separación conceptual entre (1) y (2). Esta separación se puede evidenciar en la siguiente situación. Imaginemos que el legislador ha decidido ahora que quien incumpla con la prohibición de fumar tendrá prisión de 4 a 5 años (es decir deroga la multa y establece la prisión como sanción a la prohibición de fumar). Al modificar (2), i.e al derogar la multa y crear la pena de prisión, no está modificando (1). En otros términos, si bien es cierto que se está modificando la sanción, el deber continúa siendo el mismo: no fumar. Supongamos ahora que la sanción (i.e la pena de prisión) es demandada por un ciudadano mediante una acción de inconstitucionalidad (por ejemplo, por ser una sanción desproporcionada) y que, en efecto, el tribunal constitucional tiene competencia para expulsar del ordenamiento jurídico a las normas inconstitucionales. Pues bien, ese tribunal en efecto declaró inconstitucional esa norma por considerarle desproporcionada y, en consecuencia, la expulsó del ordenamiento jurídico.

Como se ve, la expulsión de la norma es establecía la sanción (o lo que es lo mismo, la expulsión de esa sanción del ordenamiento jurídico), no es una con-

25 Kelsen pensaba que una característica necesaria de las normas jurídicas era la existencia de sanciones en los casos de incumplimiento. Para él, en otras palabras, afirmar que una conducta $\varnothing$ es jurídicamente exigida equivale a afirmar que la conducta contraria $(-\varnothing)$ es sancionable. 
dición ni necesaria, ni suficiente para argumentar que no existe el deber jurídico de no fumar. De hecho, a pesar de que la sanción este derogada, no significa que ahora este permitido fumar. Puede incluso ser el caso que una autoridad exija a un individuo apagar un cigarrillo en un lugar no autorizado, aun cuando -desde luego- no podrá imponer la multa, ni mucho menos la prisión. Lo explicado hasta este punto es suficiente para demostrar que las sanciones son contingentes para explicar la existencia y funcionamiento de los deberes jurídicos.

De acuerdo con lo dicho, en la explicación de las normas prescriptivas es necesario diferenciar entre el fundamento de la exigencia de determinadas conductas y las eventuales sanciones que puede disponer el sistema jurídico para motivar el cumplimiento de esas exigencias. Y lo cierto es que ni la explicación de las sanciones se puede reducir a la explicación de los deberes, ni los deberes se pueden reducir a la explicación de sanciones. De hehco, afirmar que existe un deber jurídico no implica que exista una sanción jurídica. No quiere decirse que no concurran relaciones al respecto. Lo que se quiere mostrar es que las sanciones jurídicas no pueden ser conceptualizadas como un elemento necesario de los deberes jurídicos. En realidad, son las sanciones las que dependen de la existencia de un deber jurídico. En otras palabras, toda sanción jurídica depende de que exista un deber cuya inobservancia justifique la creación de la sanción ${ }^{26}$. Aun cuando entre deberes y sanciones no exista una relación conceptual o constitutiva, si existe una relación justificatoria: la existencia de un deber jurídico debe formar parte de la justificación de la existencia de una sanción jurídica. En otras palabras, aun cuando un deber no sea una razón suficiente para la existencia de una sanción, la existencia de una sanción supone un deber que tiene la capacidad de justificar la sanción.

Como se dijo antes, además de las normas que regulan la acción de los individuos, los ordenamientos jurídicos están conformados por reglas secundarias que establecen las condiciones para identificar, crear, modificar, derogar o aplicar las normas jurídicas. Dentro de estas normas secundarias, las normas de competencia establecen las condiciones en que un sujeto $S$, mediante el procedimiento $P$, es competente para generar los actos normativos $N$. Existe una diferencia fundamental en relación con las consecuencias del desconocimiento de esas normas ${ }^{27}$. Por una parte, las sanciones son las consecuencias que el ordenamiento jurídico -y

26 Lamond, G., Coercion and the Nature of Law, op. cit., pp. 35-57.

27 Ferrer, J., Las normas de competencia. Un aspecto de la dinámica jurídica, Centro de Estudios Políticos y Constitucionales, Madrid, 2000. 
de forma contingente- puede disponer para los casos de desconocimiento o violación de las conductas exigidas por las normas prescriptivas. Por otra parte, las nulidades (en amplio sentido ${ }^{28}$ ) son las consecuencias del desconocimiento de las normas de competencia. En el caso de las normas prescriptivas es posible separar la el deber jurídico de la sanción (y, de hecho, la primera subsiste aun cuando no exista la segunda). Por el contrario, en el caso de las normas de competencia no es posible separar la nulidad del contenido de la norma. Por ello, en el caso de las normas prescriptivas tiene sentido afirmar que la conducta es obligatoria (vr.gr. no fumar) aun cuando no exista sanción (como en el caso hipotético mencionado arriba). Por el contario, no tiene sentido establecer los requisitos para la celebración de un contrato de compraventa (acuerdo, cosa y precio), si en todo caso ese acto jurídico es válido si no se respetan esos requisitos ${ }^{29}$.

Como se puede ver, las nulidades son la consecuencia de no observar las condiciones establecidas en las normas de competencia. Estas normas, se reitera, no prescriben conductas, sino que definen las condiciones que posibilitan la creación de actos normativos (sentencias, leyes, contratos, etc.). Las nulidades, por tanto, no son la consecuencia de incumplir una prohibición o de actuar en contra de una obligación, sino la consecuencia de no haber seguido ciertos parámetros o requisitos anteriormente establecidos por una regla secundaria ${ }^{30}$.

Por tanto, es conceptualmente posible una norma prescriptiva sin sanción y conceptualmente imposible una norma de competencia sin nulidad. Es decir, a diferencia de la relación entre normas prescriptivas y sanciones (que, como vimos, es contingente y justificatoria), la relación entre normas de competencia y nulidades es conceptual y necesaria. El incumplimiento de una norma de competencia implica la nulidad (en amplio sentido) de los actos. Las sanciones

28 Por nulidad en amplio sentido entiendo la consecuencia ante el incumplimiento de reglas que confieren competencias o potestades y que puede llevar a que los actos inexistentes, inválidos, inexequibles etc.

29 Dejo por fuera del análisis las diferencias entre las distintas modalidades (invalidez, inexistencia, inexequibilidad, nulidad, anulabilidad, etc.) que, al respecto, pueden aparecer en los ordenamientos jurídicos

30 Imaginemos una regla de competencia que contiene los requisitos que debe cumplir la decisión de un juez para ser considerada «sentencia». Simplificando la cuestión, la regla establece que la validez jurídica de la sentencia depende de que el juez a) tenga competencia sobre el asunto, b) evidencie los hechos probados, b) articule y exponga las razones que justifican la decisión, basándose en las normas jurídicas vigentes y c) establezca explícitamente la decisión en la parte resolutiva de la sentencia. En tanto regla de competencia, la del ejemplo define las condiciones de validez de las sentencias judiciales, o lo que es lo mismo si y un acto no cumple con alguna de esas condiciones es inexistente o nulo 
pretenden, como vimos, motivar (mediante la amenaza de un castigo) el cumplimiento de acciones que, en todo caso, son obligatorias. Las normas de competencia, por el contrario, no exigen conductas, sino que posibilita la realización de actos jurídicos. Si no se cumplen estas normas entonces el acto jurídico será nulo, pero no por ello se puede concluir que se está castigando a una persona ${ }^{31}$.

¿Esto quiere decir que no es posible contemplar sanciones en relación con las normas de competencia? En estricto sentido no. Las normas de competencia, se reitera, establecen las condiciones para que un acto jurídico pueda ser creado, modificado, derogado o aplicado. Si los individuos no cumplen con alguna de estas condiciones la consecuencia es que el acto jurídico que pretendían realizar será nulo. Es decir, la consecuencia jurídica ante el incumplimiento de una norma de competencia es la nulidad del acto. Sin embargo, al respecto es necesario hacer algunas precisiones. Lo que si es posible es que en el ordenamiento jurídico se contemplen deberes cuyo contenido incluye la realización de un acto jurídico y por tanto el seguimiento de normas de competencia. Supongamos que el legislador formula las disposiciones jurídicas D1, D2 y D3. Mediante D1 define las condiciones $p$ y $q$ necesarias para la validez del acto $t$. D2 establece que es obligatorio para un conjunto de individuos $i$ realizar los actos $t$. $\mathrm{D} 3$, por último, establece una sanción para los casos en que los individuos no realicen $t$, es decir para aquellos $i$ que no cumplen la obligación establecida en D1. No obstante, esto no significa que la sanción sea consecuencia del incumplimiento de la regla secundaria pues, como se ve, es una eventual consecuencia del incumplimiento de la regla formulada en D2 ${ }^{32}$.

Una sentencia juridicial, por ejemplo, es un acto jurídico cuya validez depende del cumplimiento de las condiciones establecidas en reglas de competencia (vr. gr. competencia, procedimiento, motivación y formalidades especificas). Si los jueces no cumplen con tales condiciones sus sentencias serán nulas. Pero además de ello, los ordenamientos jurídicos contemplan el deber de que los jueces resuelvan, mediante sentencias, los casos sometidos

31 Pensemos, por ejemplo, que para realizar un contrato de compraventa se deba ser mayor de edad. Nicolás, un niño de 10 años, decide entregar un libro a Martín en contraprestación de $\$ 5.000$. Este acto, en tanto incumple una condición establecida en una regla secundaria (ser mayor de edad) es nulo. Sin embargo, no es posible sostener que se esté castigando a Nicolás, ni que el propósito de la regla secundaria -y su correlativa nulidad- sea el de motivar una conducta mediante amenazas, más bien obedece a la intención de proteger al individuo

32 Este asunto ha sido analizado, en el marco de la noción de inhabilidades e incompatibilidades en el derecho público, en BARRETO-Moreno, A.A. y Pulido-OrTiZ, F.E., «El carácter sancionatorio del régimen de inhabilidades e incompatibilidades», Revista furídicas, 16 (2018), pp. 153-171. 
a su competencia. Por lo tanto, en relación con las sentencias es posible diferenciar entre a) las reglas secundarias que definen las condiciones de validez de las sentencias y b) las reglas primarias que establecen el deber de los jueces de proferir sentencias. Deber, que incluso, como, puede justificar la creación sanciones penales (vr. gr. el prevaricato) o disciplinarias.

Puede ocurrir también que el contenido de una norma sancionatoria corresponda a una propiedad que hace parte de una regla secundaria. Pensemos que el legislador formula las siguientes disposiciones jurídicas. D4 establece las condiciones $p, q, r$ para la validez de un acto jurídico «A»; D5 establece el deber de hacer Ø; y D6 establece la sanción para motivar el cumplimiento de la regla formulada en D5. Pero además, dentro de la sanción establece que la propiedad $z$ que afecta las propiedades definidas en D4 para la validez de «A». D6, además de formular una sanción, está definiendo una propiedad adicional que formará parte de las reglas secundarias del ordenamiento jurídico. Supongamos que «A» se refiere a un contrato con el estado y que, para ello, D4 establece las siguientes condiciones de validez: ser una persona capaz ( $p$ ), perfeccionar un acuerdo de voluntades $(q)$ y reunir las condiciones establecidas en los términos de condiciones $(r)$. Por otra parte, D5 establece el deber de los ciudadanos colombianos de declarar renta y, de ser el caso, de pagar los impuestos respectivos. Por último, D6 establece como sanción, para motivar el cumplimiento del deber establecido en D5, una multa y que quienes sean sancionados no podrán celebrar contratos con el estado. Esto quiere decir que D5 estableció como sanción una propiedad que se adiciona a las establecidas en $\mathrm{D} 4$, de tal forma que a las condiciones $\mathrm{p}, \mathrm{q}, \mathrm{r}$ para realizar el acto jurídico (contrato con el estado) se adicionó una nueva condición: no haber sido sancionado por no declarar renta o por no pagar los impuestos respectivos.

Es cierto que los ordenamientos jurídicos planteen relaciones complejas entre las normas prescriptivas y las de competencia, y entre sanciones y nulidades. Pero ello no quiere decir que las reglas de competencia se puedan reducir a sanciones, ni que las nulidades se puedan concebir como un tipo especial de sanciones.

\section{El carácter organizado de las sanciones jurídicas}

El carácter contingente de las sanciones se evidencia en el hecho que los sistemas jurídicos contemporáneos establecen dos condiciones generales para poder establecer sanciones. En primer lugar, las autoridades jurídicas pueden 
crear sanciones solo si existe un deber jurídico que justifique la sanción. Esto supone que existe un deber previo o independiente (por ejemplo el deber de no fumar) que justifica la creación de la sanción (por ejemplo la multa). En segundo lugar, las sanciones jurídicas dependen necesariamente de reglas positivas, es decir de disposiciones jurídicas específicas que establezcan la sanción. No es posible, por tanto, la existencia de sanciones jurídicas necesarias, o lo que es lo mismo, toda sanción debe ser creada y regulada por disposiciones jurídicas vigentes.

De acuerdo con esto último, la segunda característica de las sanciones jurídicas es su carácter reglado, en el sentido que es el propio derecho el que, por medio de las autoridades jurídicas, define las reglas para la creación y aplicación de sanciones. Tiene razón Kelsen cuando afirma que un rasgo distintivo de los ordenamientos jurídicos consiste justamente en que las sanciones y su aplicación están previstas por ese orden ${ }^{33}$. Sin embargo, Kelsen no logró advertir que el carácter reglado de las sanciones no significa que necesariamente sean creadas y aplicadas por las autoridades jurídicas. En este sentido, es posible imaginar un sistema jurídico en el cual tales funciones no están en poder de las autoridades jurídicas sino dejadas en mano de los partes afectadas o ejecutadas por agencias privadas ${ }^{34}$. En efecto, no es extraño que nuestros sistemas jurídicos deleguen a los particulares la función de crear sanciones (vr. gr. la cláusula penal en un contrato) y la de aplicarlas (vr. gr. un árbitro privado el que defina la aplicación o no de la sanción).

En suma, una característica fundamental de las sanciones en el derecho es que son las normas jurídicas las que regulan (bien sea a través de su propias autoridades u otorgando potestades a particulares) la forma en que se crean y aplican las sanciones. En otros ordenamientos normativos (por ejemplo las normas de etiqueta) es posible que existan reglas que, de alguna forma, contemplen sanciones. Pero el funcionamiento de las sanciones en esos ordenamientos normativos no depende de una organización encargada de crear, regular y aplicarlas. No significa que, eventualmente, las sanciones por incumplir normas de etiqueta puedan organizarse institucionalmente (pensemos, por ejemplo, en un club privado). Pero, mientras que en el derecho el carácter regulado es un elemento característico de la forma como funcionaban las sanciones, en otros ordenamientos normativos esa es una característica

33 Kelsen, H., «The Law as a Specific...», op. cit., pp. 79-80.

34 LAMOND, G., «Coercion and the Nature of Law», op. cit., p. 39. 
contingente. Es decir, a diferencia de otros ordenamientos normativos en los que las sanciones pueden o no regularse, en el derecho es una característica fundamental que las sanciones jurídicas estén reguladas e institucionalmente organizadas. No quiere decir que las sanciones sean un elemento necesario de la naturaleza del derecho. Lo que ocurre es que aun cuando las sanciones son una característica contingente en la explicación de las normas jurídicas, lo cierto es que las sanciones jurídicas en el derecho son creadas por el propio ordenamiento jurídico y su aplicación regulada por sus normas. En otras palabras, afirmar el carácter reglado de las sanciones jurídicas significa que su existencia y aplicación depende del propio derecho.

Desde luego que pueden existir sistemas normativos -independientes del derecho- que contemplen sanciones por el incumplimiento de las normas jurídicas. Pensemos -por ejemplo- el caso de un grupo social que tiene establecido que si se acredita que un miembro no paga los impuestos será expulsado de la organización. Por ello, Lamond señala que las sanciones pueden provenir de otros sistemas normativos que coexisten con el derecho en las sociedades contemporáneas. En particular las reglas sociales pueden proveer de sanciones a quienes no siguen las normas jurídicas y estas sanciones claramente no son definidas por el derecho mismo (es decir, no están reguladas por las normas jurídicas). Pero este fenómeno -que desde luego es contingente a cada sociedad en particular-no explica las sanciones jurídicas ${ }^{35}$. Lo que resulta paradigmático de las sanciones jurídicas, a diferencia de las sanciones sociales, es -como se ha dicho- su carácter reglado, esto es que la creación deliberada de las sanciones y la regulación de su aplicación.

\section{Las sanciones como fuentes de motivos para la acción}

La relación entre las normas prescriptivas y las sanciones jurídicas es contingente y justificatoria. Es contingente porque los deberes que establecen esas normas son conceptualmente independiente de las sanciones. Y es justificatoria porque la justificación de las sanciones depende de la existencia de deberes. La última característica de las sanciones que me interesa resaltar está en función de estas relaciones. La finalidad de las sanciones es motivar a los individuos a actuar de conformidad con los deberes jurídicos. Teniendo en

35 Ibidem. 
cuenta la distinción entre el deber jurídico (vr. gr. «no fumar») y la sanción (vr. gr. «la multa»), entonces el propósito de la sanción es motivar a los individuos para que actúen de conformidad con el deber: la multa busca motivar a los individuos para que no fumen.

Ahora bien, las sanciones motivan a los individuos a actuar de conformidad con sus deberes jurídicos mediante la definición de consecuencias negativas (sanciones negativas) o positivas (sanciones positivas) para los casos de conductas contarías al deber en el primer caso, o de conductas conformes al deber en el segundo caso. Las sanciones, por tanto, son negativas cuando establecen una amenaza a la conducta contraria a la exigida (v. gr. la multa en los casos de fumar en lugares prohibidos), y son positivas cuando se establece un premio a la realización de la conducta exigida (el que vote tendrá derecho a un día de descanso compensatorio pago) ${ }^{36}$.

Las sanciones, por lo dicho, pretenden motivar a los individuos para que actúen conforme a los deberes jurídicos. Como se recordará, de acuerdo con Kelsen, en los sistemas normativos es posible diferenciar dos formas de motivación ${ }^{37}$. La motivación directa depende de que los individuos actúen motivados por los deberes. Así, un individuo actúa motivado directamente cuando realiza la conducta por el deber mismo (yo no fumo porque no debo fumar). En la motivación indirecta, por el contrario, el orden normativo atribuye ventajas (sanciones positivas) a quienes actúan conforme a los deberes o desventajas (sanciones negativas) a quienes actúan en contra de los deberes. Por lo tanto, un individuo actúa motivado indirectamente por las sanciones cuando actúa conforme al deber por la sanción (yo no fumo porque no quiero pagar la multa). Por lo tanto, la motivación que buscan las sanciones es indirecta toda vez que no pretenden motivar a los individuos indicando la acción que debe ser realizada (la norma sancionatoria no motiva a través del deber) sino que motivan el cumplimiento de los deberes amenazando con castigar las conductas contrarias (motiva la amenaza de la multa) o premiando las conductas conformes (motiva la expectativa de un día adicional de descanso) $)^{38}$.

36 Kelsen, H., Teoría Pura del Derecho, op. cit., pp. 38-39; y SCHauer, F., «The Force of the Law», op. cit., p. 123.

37 Kelsen, H., «The Law as a Specific...», op. cit., pp, 75-97; y YANKAH, E., «The Force of Law...», op. cit., pp. 1195-1256.

38 Kelsen, H., Teoría Pura del Derecho, op. cit.; ID., The Law as a Specific..., op. cit., pp, 75-97 1941; y NINO, C., La validez del Derecho, Astrea, Buenos Aires, 1985. 
Para comprender en qué sentido se puede afirmar que las sanciones motivan la conducta de los individuos, resulta oportuno recurrir a la distinción entre dos formas de referirse a las razones para la acción: las razones justificactorias y las razones motivadoras ${ }^{39}$. Una razón para la acción es justificatoria cuando se constituye en una consideración a favor de una acción determina$\mathrm{da}^{40}$ (conocer el fundamento del derecho justifica estudiar teoría del derecho). Por su parte, las razones motivadoras (o motivos) son las consideraciones que hacen parte del conjunto o aparato motivacional del individuo, es decir, las razones que el individuo en efecto tienen en cuenta respecto de cómo actuar ${ }^{41}$ (Juan tiene examen de teoría del derecho y sabe que si no estudia es muy probable que repruebe la materia. La probabilidad de perder el examen motivo a Juan a estudiar teoría del derecho).

Es necesario hacer tres precisiones acerca de las relaciones y diferencias entre las razones justificatorias y las razones motivadoras. Primero, una razón motivadora no es una condición suficiente de la acción. Sostener, por ejemplo, que $q$ es un motivo para que un individuo realice la acción $\varnothing$, no significa que $q$ sea una condición suficiente para la acción, pues puede ser que $q$ forme parte del aparato motivacional del individuo, pero aun así este decida actuar en contra de $q^{42}$. En la deliberación de Juan se consideró el hecho de estudiar para aprobar el examen. Sin embargo, y a pesar de su deliberación, Juan decidió no estudiar (imaginemos que no lo hizo porque prefiero ver una divertida serie de televisión).

39 La distinción entre razones motivadoras y justificatorias puede verse en SMITH, M. Valuing: desiring or believing. Reduction, Explanation and Realism, D. Charles y K. Lennon (ed.), Oxford University Press, Oxford, pp. 324-328, Audi 2004: 120-122; y FARRELL, M., Entre el Derecho y la Moral, Abeledo Perrot, Buenos Aires. Para una crítica de la distinción véase ZAMBrano, P., «El derecho como razón excluyente para la acción: una aproximación desde la teoría iusnaturalista del derecho de John Finnis», Problema. Anuario de Filosofía y Teoría del Derecho, 4 (2010), pp. 323 366. No pretendo, en todo caso, involucrarme en este trabajo en la discusión acerca de si estos tipos de razones están necesariamente conectadas, o si por el contrario es posible afirmar la existencia de razones justificatorias desconectadas de los motivos. Lo que propongo es emplear esta distinción para explicar y hacer inteligible el funcionamiento de las normas jurídicas que establecen sanciones.

40 Raz, J., Practical Reason and Norms, Oxford University Press, Oxford, 1990.

41 AUDI, R., «Reasons, practical reason, and practical reasoning», Ratio an International fournal of Analytic Philosophy, 17 (2004), pp. 119-149.

42 Para explicar esto, Audi diferencia entre las razones poseídas (possessed reasons) y razones motivadoras en estricto sentido. Las primeras son aquellas que un individuo tiene, es decir que forman parte de su conjunto motivacional. Las segundas son aquellas que, en efecto, llevaron al individuo a actuar de determinada manera. Reasons, practical reason, and practical reasoning (AUDI, R., «Reasons, practical reason...», op. cit., pp. 119-149. 
Así las cosas, si la norma $\mathrm{N}$ exige la conducta Ø y contempla la sanción $\mathrm{S}$, el propósito de $\mathrm{S}$ es constituir un motivo para que los individuos realicen $\varnothing$. Sin embargo, esto no significa que si $S$ constituye un motivo para que el A realice $\varnothing$. En otras palabras, aun cuando $S$ forme parte de la deliberación de A, esto no es una condición suficiente para que A realice $\varnothing$, ni que si el individuo realiza $\varnothing$ su acción haya sido causada necesariamente por S. Las sanciones, por tanto, están diseñadas para motivar a los individuos a realizar determinadas acciones, es decir para dar a esos individuos motivos adicionales para realizar esas acciones. Las sanciones, en definitiva generan una razón auxiliar que opera cuando la razón justificatoria no logra motivar. Pero como los motivos no son condición suficiente para la acción, es posible el caso que las sanciones se constituyan en motivos para que el individuo realice $\varnothing$, pero aun así el individuo no realice $\varnothing$. En otras palabras, que las sanciones se constituyan en motivos para la acción no asegura que los individuos realicen la respectiva acción.

Segundo, no existe equivalencia conceptual entre las razones justificatorias y los motivos. Piénsese en este otro ejemplo. Juan mató a Luis porque este no le pagó una deuda. Se dirá, entonces, que la deuda fue el motivo de Juan para matar a Luis. Pero no se puede afirmar que la deuda justifique la acción de Luis, es decir, que sea una razón a favor de la conducta de Luis. La deuda, en este caso, es un motivo, pero no una razón justificatoria. Además, las razones justificatorias pueden formar o no parte de la motivación del individuo. Es decir, no hay necesidad alguna que exija que las razones justificatorias se constituyan en motivos para la acción. En efecto, puede ocurrir que un individuo actúe por motivos contrarios a lo exigido por una razón justificatoria, como sucede en el caso de Luis ${ }^{43}$. Obsérvese que, por cuanto el propósito de las san-

43 Sobre la forma como operan los motivos en la deliberación práctica y su incidencia en la acción intencional véase ZAMBRANO, P., «El derecho como razón excluyente...», op. cit., pp. 323-366. Debe aclararse que la profesora Zambrano piensa que toda razón justificatoria es por naturaleza un motivo para la acción, particularmente porque es lo que explica la acción intencional la que indefectiblemente está volcada a algún tipo de bien. No es posible en este trabajo resolver esta compleja cuestión, sin embargo creo que en las dos posiciones subyacen dos puntos de vista distintos. La profesora Zambrano busca explicar la acción intencional de abajo hacia arriba, es decir dando cuenta de la forma en que operan las acciones humanas para luego relacionarla con la forma en que opera el derecho. Desde esta perceptiva es cierto que toda razón justificatoria motiva en tanto toda deliberación práctica incluye una razón justificatoria. Por otro lado, lo que yo pretendo en mi explicación es elucidar la forma en que operan las normas y sus relaciones con las razones para la acción. Por una lado, las normas que exigen conductas pretenden generar razones justificatorias. Puede ocurrir sin embargo que, aun cuando esas normas sean fuente de 
ciones es motivar la conducta de los individuos, estas son independientes de si la conducta motivada se justifica o no. Para explicar de qué manera las sanciones pueden, certeris paribus, justificar la acción, suele recurrirse a su capacidad para ser fuente de razones prudenciales para la acción, i.e aquellas que se fundamentan en un cálculo autointeresado entre las ventajas y desventajas de un determinado curso de acción: tener una razón prudencial para hacer $\varnothing$, implica una alta probabilidad de que hacer $\varnothing$ incremente los intereses individuales del agente $^{44}$. Las sanciones, como se dijo, amenazan con imponer consecuencias negativas a los individuos, es decir con privar de algún bien a los individuos (vr. gr. la vida, la libertad, su dinero etc), lo cual hace que los individuos tengan una razón para maximizar sus intereses (en este caso que no sean privados de sus bienes) ${ }^{45}$. De la relación entre las sanciones y la justificación de la acción se puede resaltar que a) las sanciones no solo son constitutivas de motivos para la acción, sino además, razones prudenciales (y en ese sentido justificatorias) para la acción; b) las sanciones pueden llegar a justificar prudencialmente la acción si es el caso que resulte probable que las sanciones sean efectivamente impuestas; y c) las sanciones, y las eventuales razones prudenciales que ellas generen, son independientes de la justificación moral de la acción ${ }^{46}$.

Lo que se intenta resalta aquí es que, aun cuando es cierto que las sanciones pueden ser fuente de razones prudenciales para la acción, lo fundamental en su funcionamiento práctico es su capacidad de constituirse en motivos para la acción. En otras palabras, la noción de razones prudenciales no es suficiente para explicar cómo las sanciones jurídicas pretenden operar en el razonamien-

razones justificatorias, no logren motivar a los individuos. Las sanciones, por otro lado, no buscan justificar la acción, lo que buscan es motivar (mediante la coerción) que los individuos actúen de conformidad con sus deberes.

44 Richardson, H., «Moral Reasoning», The Stanford Encyclopedia of Philosophy, Winter 2014 Edition, Edward N. Zalta (ed.), URL = https://plato.stanford.edu/archives/win2014/entries/ reasoning-moral/

45 No pretendo ocuparme de la compleja cuestión sobre si las razones prudenciales pueden constituir razones justificatorias o si solo las razones morales pueden justificar las acciones. En todo caso, suele ocurrir que estas razones pueden justificar la acción, en la medida que su contenido sea moral, por ejemplo, cuando los bienes o el interés que resguardan tienen un valor intrínseco, como el de proteger la vida.

46 Sobre la diferenciación kantiana entre justificación moral y prudencial de la acción véase RICHARDSON, H., «Moral Reasoning...», op. cit. Debe aclarase que el concepto de «prudencia» se emplea en el sentido usado por Hume y Kant, y no la «prudencia» desde un punto de vista aristotélico-tomista de acuerdo con el cual lo prudente es una razón justificada en bienes reales para obrar. 
to práctico de los individuos, pues aunque es cierto que las sanciones jurídicas pueden generar razones prudenciales para que los individuos actúen conforme a las reglas jurídicas, lo característico de las sanciones es su pretensión de motivar a los individuos. Para ello, las sanciones pretenden interferir en la deliberación práctica de los individuos, mediante la amenaza que genera en ellos la eventual imposición de una consecuencia negativa. De esta forma, lo fundamental en el análisis de las sanciones (negativas), a diferencia de lo que ocurre con las razones prudenciales en general, es la forma como la amenaza (la coerción, como se verá en el siguiente punto) se constituye en un motivo para la acción de los individuos

Tercero, es posible diferenciar entre actuar en cumplimiento de una razón justificatoria (ie. motivado por una razón justificatoria) y actuar de conformidad con una razón justificatoria (ie cuando la razón justificatoria no hace parte del conjunto motivacional del individuo). Puede ocurrir que un individuo actúe según lo exigido por una razón justificatoria, aunque no haya sido motivado por ella. Imaginemos que una ley de impuestos es una razón que justifica que Pedro pague $x$ suma de dinero. Sin embargo, puede ser que esta razón no forme parte de las consideraciones de Pedro sobre lo que debe hacer con su dinero. Pedro, al creer que solo estaba pagando un recibo del agua, pagó el impuesto que estaba incluido en ese recibo. En este caso, Pedro actuó según una razón justificatoria, aunque esta no motivó su deliberación práctica. Para dar cuenta de este tipo de situaciones, Raz propone la diferenciación entre actuar en cumplimiento (compliance) y actuar de conformidad (conformity) con las razones. Un individuo actúa en cumplimiento de una razón $\rho$, cuando la identifica como una razón para realizar $\varnothing$ (es decir, $\rho$ se internaliza y se constituye en un motivo para hacer $\varnothing$ ), y en consecuencia, actúa. Por otra parte, un individuo actúa de conformidad con $\rho$, cuando realiza $\varnothing$ sin haber sido motivado por $\rho^{47}$.

47 RaZ, J., Practical Reason and Norms, op. cit., pp. 178-182. Estas distinciones son similares a las planteadas por Kant al explicar la noción de buena voluntad, esto es aquella que es en sí misma buena y no «por lo que produzca o logre, ni por su idoneidad para conseguir un fin propuesto» (KANT, I., Fundamentación para una metafísica de las costumbres, versión castellana y estudio pre-

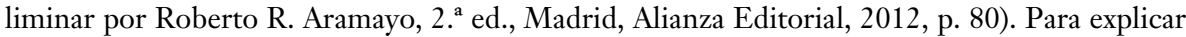
el concepto de una voluntad buena en sí misma, Kant abordó la noción de deber. La buena voluntad depende de que el sujeto actúe de conformidad con el deber. Ahora bien, en esta explicación consideró necesario distinguir diferentes escenarios en los que un sujeto puede actuar conforme a un deber, esto es realizar la acción indicada por un deber (ibid., 85-87): 1. Actuar de conformidad al deber como resultado de una motivación independiente al deber. Las acciones de un sujeto pueden coincidir con las exigidas por el deber, pero que son ejecutadas como consecuencia de otro tipo de motivaciones que los llevan a actuar de esa manera. En este escenario, las acciones «son efectivamente conformes al deber», y aunque los sujetos «no poseen ninguna 
En otras palabras, cuando un individuo actúa en cumplimiento de una razón justificatoria, esto significa que fue motivado por ella; por otro lado, si actúa de conformidad con una razón, realiza la acción justificada por esa razón, aunque esté motivado por otras consideraciones.

Por lo tanto, afirmar que las sanciones son una técnica de motivación corresponde a sostener que el propósito de las sanciones es constituirse en motivos para la acción, es decir, formar parte del conjunto motivacional de los individuos. El propósito de las sanciones es que los individuos actúen de conformidad a los deberes jurídicos, es decir que actúen de conformidad a lo exigido por las normas jurídicas prescriptivas, aun cuando no estén necesariamente motivados por ellas. De esta manera, el funcionamiento de las sanciones en el razonamiento práctico depende de su capacidad para que los individuos actúen motivados por ellas, esto es que se constituyan en un motivo para la acción de los individuos.

\section{SANCIONES JURÍDICAS Y COERCIÓN}

En el apartado anterior se señalaron tres características fundamentales de las sanciones jurídicas: (1) la separación conceptual entre las normas jurídicas y las normas jurídicas que definen y regulan sanciones; (2) el carácter reglado de las sanciones jurídicas; y (3) la pretensión motivadora de las sanciones. De

inclinación inmediata», las realizan «porque alguna otra inclinación les mueve a ello» (ibid., 86). 2. Actuar por una inclinación inmediata al deber, esto es cuando el sujeto tiene una motivación auto-interesada en el cumplimiento del deber. Así, «conservar la propia vida supone un deber y además cada cual posee una inmediata inclinación hacia ello». Sin embargo, conservar la vida para asegurar nuestra propia subsistencia corresponde a una acción conforme al deber motivado por la inclinación inmediata que genera en el sujeto proteger su vida, pero no es una acción por el deber mismo. c) Actuar por deber, por el contrario, se refiere a aquellas acciones en las que el sujeto actúa conforme al deber desinteresadamente, esto es, actuar por el deber mismo (ibid., p. 87). De acuerdo con lo anterior, una primera regla para una buena voluntad corresponde a quien actúa conforme al deber por el deber mismo, es decir sin otra motivación que la de cumplir el deber (la otra regla estará en función de la noción de imperativo categórico, cuyo análisis no corresponde ni compromete a lo presentado en este escrito). Por ello, para Kant, una acción tiene valor moral solo cuando es resultado de la buena voluntad, esto es cuando es el resultado de hacer el bien por el deber (ibid., p. 89). Ahora bien, lo que pretende mostrar Kant con estas distinciones es que el carácter moral de una acción no está en función de su propósito, sino en el deber que regula la acción. De esta manera, los propósitos o fines que la voluntad persigue no confieren valor moral a la acción. Una acción es moral solo si es realizada por buena voluntad, esto es -se reitera- cuando el individuo actúa por el deber mismo-. Por ello, la buena voluntad depende de que el deber se constituya en el la única razón que motiva a la acción. 
acuerdo con esta última característica, la pregunta sobre la naturaleza de las sanciones apunta a establecer cómo cumplen su función en la dirección de la conducta de los individuos. Se trata de definir cómo las sanciones logran formar parte del conjunto o aparato motivacional de los individuos.

Existe una sanción (negativa) cuando el ordenamiento jurídico contempla una amenaza (i.e la posibilidad de que le sea impuesta una desventaja) a la realización de conductas contrarias a las exigidas. Así, como se ha dicho, lo característico de las sanciones es que pretenden motivar la conducta mediante la presión que genera en los individuos la probabilidad de que la amenaza se haga efectiva. Desde este punto de vista, la coerción puede ser definida como la presión generada efectivamente en la deliberación practica de los individuos, a consecuencia de la probabilidad de la imposición de la sanción ${ }^{48}$. En otras palabras, cuando la amenaza de la imposición de las consecuencias negativas definidas en la sanción es internalizada por los individuos (i.e cuando forma parte de su conjunto motivacional), se dice que estos son o están coercionados ${ }^{49}$.

La explicación de cómo la coerción opera en el razonamiento práctico, vía amenaza o presión generada por la probabilidad de la imposición de la consecuencia negativa establecida en la sanción, fue iniciada por Nozcik ${ }^{50}$. Se-

48 Desde luego que la coerción no se reduce a los casos de sanciones (ANDERSON, S., «Coercion», Stanford Encyclopedia of Philosophy (2015), Edward N. Zalta (ed.), URL = https://plato.stanford. edu/archives/sum2015/entries/coercion/. Entre otros, se pueden mencionar las siguientes situaciones en las que la coerción es jurídicamente relevante de forma independiente a las sanciones. Primero, la coerción es considerada como una causal de ausencia de responsabilidad penal. Segundo, en el derecho civil la coerción es una de las causales que vician el consentimiento de las personas. Lo cierto es que los diferentes roles que cumple la coerción en el derecho no pueden ser capturados por medio de un solo concepto de coerción (LAMOND, G., «Coercion», en A Companion to Philosophy of Law and Legal Theory, Dennis Patterson [ed.], Wiley-Blackwell, Oxford, 2010, p. 645). Por esta razón, las conclusiones a las que se pueda llegar en las siguientes líneas se circunscriben al concepto de coerción en relación con las sanciones jurídicas.

49 No es posible desarrollar acá el tipo de «presiones» que pueden considerarse como coercitivas. Sobre el particular puede verse LAMOND, G., «The Coerciveness of Law», Oxford fournal of Legal Studies, 20 (2000), pp. 39-62; y LAMOND, G., «Coercion», op. cit., pp. 642-653.

50 Nozick, R., Coercion, Philosophy, Science, and Method: Essays in Honor of Ernest Nagel, Sidney Morgenbesser, Patrick Suppes, and Morton White (eds.), St. Martin's Press, New York, 1969, pp. 440472. Este tipo de coerción ha sido denominada «coerción disposicional» (dispositional coerción) para diferenciarla de la «coerción física» (occurrent coercion). La segunda procede por imposición física -A impone físicamente a $\mathrm{B}$ la acción $\mathrm{X}$ - mientras que la primera segunda procede mediante inducción -A motiva a B realizar la acción X- (BERMAN, M., «The Normative Functions of Coercion Claims», Legal Theory 8 [2002], pp. 45-89). Así, por ejemplo, Luisa puede empujar a Iván al rio para nada, o Luisa puede amenazar a Juan para que nade en el Rio, anunciándole que si no lo hace lo calificará públicamente como cobarde. Lo que debe resaltarse es que en la 
gún este autor, la coerción surge si, y solo si: (i) A pretende evitar que B elija el curso de acción Ø. (ii) A comunica esa pretensión a B. (iii) La pretensión de $\mathrm{A}$ indica que si $\mathrm{B}$ realiza $\varnothing$, entonces $\mathrm{A}$ causará alguna consecuencia para que la acción $\varnothing$ sea menos deseable para $B$, que si B no hace $\varnothing$. (iv) La pretensión de A es creíble para B. (v) B no hace $\varnothing$. (vi) Parte de las razones para que B no realice $\varnothing$, es disminuir la probabilidad de que A cause la consecuencia anunciada en (iii). En estos términos, la coerción se refiere a los motivos de los individuos generados por el temor de que se causen las acciones anunciadas en la sanción. Esos motivos deben tener la capacidad de incidir en su deliberación práctica acerca de cómo deben actuar o decidir. Es por ello que las sanciones, por medio de la coerción, se proponen influenciar la deliberación práctica de los individuos, alterando su conjunto motivacional ${ }^{51}$. Imaginemos que Pedro invita a su amiga María a fumar un cigarrillo en el pasillo de la universidad (asúmase que el pasillo hace parte de los lugares donde está prohibido fumar). En circunstancias normales, María acompañaría a Pedro a fumar, pues es una actividad que disfruta, y además entiende que uno de los deberes de una relación de amistad es acompañar a los amigos. Es más, María cree que la regla es arbitraria y que las autoridades no tienen jurisdicción sobre asuntos privados como la decisión de fumar o no fumar. No obstante, ella responde de forma negativa a la invitación de Pedro, explicándole que es posible que alguien los sorprenda y los obligue a pagar la multa o, incluso, los arreste. En este ejemplo, la existencia de la sanción se constituye en una razón motivadora para la acción, por la cual María decide no acompañar a Pedro a fumar. Puede afirmarse, por tanto, que lo que lleva a María a negarse a acompañar a Pedro a fumar, pese a que en otras circunstancias lo habría hecho, es la coerción generada por la sanción creada en la ley.

Mediante las sanciones los sistemas jurídicos pretenden que la coerción motive a los individuos a que actúen conforme a los deberes jurídicos, aunque no sean motivados por esas reglas. Lo que motivó a María en su decisión de no acompañar a Pedro, no fue el deber de no fumar creado por la ley, sino su

coerción disposicional, la acción de B depende en alguna medida de su deliberación acerca de cómo debe actuar, mientras que en la coerción física no aparece ni la deliberación ni la voluntad del agente coaccionado. Como se verá más adelante, en este trabajo se delimita el concepto a la coerción disposicional. La coerción física aparecerá como uno de los tipos de coacción.

51 ANDERSON, S., «Coercion as Enforcement, and the Social Organisation of Power Relations: Coercion in Specific Contexts of Social Power», Furisprudence, 7 (2016), pp. 525-539. STaVropoulos, N., «The Relevance of Coercion: Some Preliminaries», Ratio furis 22 (2009), pp. 339-358. 
temor a que la sanción establecida le fuese impuesta. De esa forma, se espera que las sanciones motiven (coercionen) a los individuos a adecuar su comportamiento al exigido por las reglas jurídicas. Por eso, la función de las sanciones jurídicas en el razonamiento práctico depende de que, en efecto, ellas sean capaces, mediante la coerción que generan, de motivar a los individuos para acatar las normas jurídicas.

Las sanciones jurídicas interfieren en el razonamiento práctico de los individuos, reduciendo las alternativas de acción a través de la coerción generada por la probabilidad (o creencia en la probabilidad) de la materialización de la amenaza anunciada en la sanción, y cambiando así las circunstancias normales de la definición de cómo deben actuar los individuos. Lo que se intenta resaltar acá es que existe una conexión entre las nociones de sanción y coerción: mediante la creación de sanciones, las autoridades se proponen crear un tipo especial de razones prudenciales para la acción basadas en el autointerés de los individuos. Una vez estas razones son internalizadas por los individuos, se constituyen en motivos para que actúen de determinada manera, si es que no desean que sus intereses se vean afectados.

Debe observarse que la relación entre sanciones y coerción es una instanciación de la relación entre razones para la acción y motivos para la acción. En efecto, cuando el legislador establece la multa para los fumadores infractores, es posible que genere una razón prudencial (evitar la multa o el arresto). Si esta razón prudencial es internalizada por los individuos se convierte en un motivo que coerciona a los individuos. Obsérvese que es posible que, a pesar de que las autoridades jurídicas establezcan una sanción, no se genere objetivamente una razón prudencial. Este sería el caso en el que la probabilidad de que se aplique la sanción sea cero o cercana a cero. Sin embargo, puede ocurrir que un individuo crea erróneamente que existe una alta probabilidad de la aplicación de la sanción. Este individuo, a pesar de no tener objetivamente una razón prudencial para actuar, puede ser motivado por la coerción. En consecuencia, lo fundamental en el funcionamiento de las sanciones depende de la coerción, es decir que forme parte del conjunto motivacional de los individuos la creencia -así sea errónea- de la probabilidad de la imposición de la sanción. A su vez, aun cuando las sanciones no se internalicen (es decir, no coercionen), ello no significa que dejen de ser razones (prudenciales) para la acción. Para ilustrar esto, Oberdiek propone un ejemplo. Un dictador adopta castigos secretos ante determinadas conductas. Incluso define, también secretamente, la forma y los procedimientos mediante los cuales impondrá el castigo. Con todo, la medida del dictador, a pesar de regular el uso de la fuerza (coacción), 
no es una sanción, pues no genera coerción ${ }^{52}$. Podríamos agregar al ejemplo que el dictador está dispuesto a aplicar las sanciones y que en consecuencia existe una alta probabilidad de que los individuos serán castigados si no realizan las acciones exigidas por el dictador. Esto quiere decir que los individuos tienen razones prudenciales para realizar esas conductas aun cuando no han sido coercionados por el dictador.

En este orden de ideas, en relación con la coerción no puede trazarse una distinción entre actuar en cumplimiento y actuar de acuerdo con ella. Recuérdese que un individuo actúa en cumplimiento de una razón cuando la internaliza y realiza la conducta exigida por ella. Por su parte, actúa de acuerdo con una razón cuando realiza la conducta exigida, aunque no esté motivado por esa razón. En lo que tiene que ver con las sanciones, por ejemplo en el caso de la regla que prohíbe fumar y sanciona con multa y arresto a quien lo haga, lo que puede ocurrir es que: (a) El individuo actúe motivado por la sanción, o sea, por la coerción que esta genera (cuando María se niega a fumar por temor al arresto). (b) El individuo no internaliza la sanción, es decir, no es coercionado, pero actúa según la conducta exigida por la regla. En el evento (a), el individuo es motivado, por la coerción que genera la sanción, a actuar de acuerdo con la regla. En el evento (b), el individuo no es motivado por la coerción y actúa en cumplimiento de la regla. De esta manera, si la sanción se explica por cuanto genera motivos (mediante la coerción) para actuar conforme a los deberes jurídicos, no puede darse que un individuo actúe conforme a la sanción (es decir, no es posible que actúe según la sanción pero no motivado por esta). En tal caso, actuaría en cumplimiento del deber creado por la regla (no fumar), pero no en cumplimiento de la sanción (la multa o el arresto).

\section{SANCIONES JURÍDICAS Y COACCIÓN}

La relación entre las sanciones y la coacción es compleja, en particular porque la noción de coacción es empleada para dar cuenta de diferentes $\operatorname{asuntos}^{53}$. Por una parte, puede referirse al uso de la fuerza: hay coacción, por

52 Oberdiek, H., «The Role of Sanctions and Coercion in Understanding Law and Legal Systems», American Fournal of Furisprudence 21 (1976), pp. 71-94.

53 Un análisis de las distintas formas en que el derecho puede emplear medidas coactivas puede verse en Schauer, F., The Force of the Law, op. cit., pp. 124-139; y Berman, M., «The Normative Functions...», op. cit., pp. 45-89. 
ejemplo, cuando en un operativo de la policía se impide el tránsito de un grupo de ciudadanos que desean llegar cuanto antes a sus lugares de destino. La coacción, en este caso, puede ser definida como todo uso de la fuerza realizado por un individuo para forzar a otro a hacer o no hacer una conducta determinada (coacción $A$ ).

Por otra parte, la coacción puede referirse a la imposición efectiva de las sanciones, es decir, a los actos concretos mediante los cuales se impone la sanción a un individuo. En este sentido, la coacción no implica necesariamente el uso de la fuerza. Imagínese aquí, por ejemplo, que la sanción ante el incumplimiento de contratos con el Estado es la inhabilidad para participar en contratos futuros. Así, X, quien previamente incumplió un contrato con el Estado, no puede, a consecuencia de la sanción establecida, participar en un proceso contractual, y por tanto su propuesta no es recibida por las autoridades competentes ${ }^{54}$ (coacción B).

Por último, la coacción puede referirse al acto mediante el cual una autoridad hace que se cumpla un deber jurídico específico ${ }^{55}$. Así, A tiene un deber respecto de $\mathrm{B}$ en virtud de la norma jurídica $\mathrm{N}$. Es decir, con fundamento en $\mathrm{N}, \mathrm{B}$ debe hacer $\varnothing$ a favor de A. Puede que $\mathrm{N}$ no haya contemplado sanción jurídica alguna, es decir que no haya establecido consecuencias negativas específicas en caso de que B no realice Ø. Sin embargo, si B no realiza Ø, A puede exigir -típicamente ante un juez- que se ordene a $\mathrm{B}$, incluso por la fuerza, realizar $\varnothing$ (coacción C).

Sin lugar a dudas, las tres modalidades de actos coactivos tienen lugar en los sistemas jurídicos. Sin embargo, lo que se analiza en este trabajo es la naturaleza de las sanciones, y por tanto, el tipo de relaciones existentes entre estas y la coacción. Como se dijo, la coacción tipo A es independiente de las

54 De acuerdo con lo dicho, se equivoca Raz al afirmar que una sanción es coercitiva siempre que permita el uso de la fuerza (RAZ, J., The Concept of a Legal System: An Introduction to the Theory of a Legal System, Clarendon Press, Oxford, p. 79). En primer lugar, como ya se dijo, las sanciones son, por naturaleza, coercitivas. Es decir que una sanción no coercitiva es una sanción «fallida». Por otra parte, la coerción no depende, de forma exclusiva, de la amenaza del uso de la fuerza. Por otro lado, algunos autores sostienen que el la noción clave para explicar la coerción es la coacción, entendida como la capacidad de hacer efectivas las amenazas (enforcement account). Sobre esto último véase ANDERSON, S., «Coercion as Enforcement...», op. cit., pp. 525-539.

55 Himma ha argumentado que este concepto de coacción es una característica esencial del derecho, es sus palabras, «the authorization of coercive enforcement mechanism is a conceptually necessary feature of law» Himma, K., «The Authorisation of Coercive Enforcement Mechanisms as a Conceptually Necessary Feature of Law», Furisprudence, 7 (2016), p. 594. 
sanciones, pues de hecho gran parte de ese tipo de actos coactivos no son sancionatorios (como el caso del operativo policial del ejemplo). Además, no todo acto de imposición de sanciones, como también se dijo, es efectuado mediante el uso de la fuerza (como en el caso de la sanción por incumplimiento de contratos con el Estado ${ }^{56}$. En este orden de ideas, no existe relación o conexión conceptual necesaria entre las sanciones jurídicas y la coacción tipo A, ni tampoco, en consecuencia, entre sanción y uso de la fuerza.

Cabe hacer una observación adicional sobre la contingencia de la coacción A, en la elucidación del funcionamiento de las sanciones jurídicas en el razonamiento práctico. Hay una conocida distinción entre las acciones humanas voluntarias e involuntarias, y una de sus características es la presencia de la razón práctica en la primera, y su ausencia en la segunda. Se supone que todo acto intencional debe estar precedido por motivos. Por el contrario, las acciones involuntarias son acciones no intencionales, y por lo tanto, no están precedidas de motivos. De acuerdo con esto, los motivos generados por las sanciones jurídicas a través de la coerción, tienen la capacidad de formar actos humanos intencionales. Por el contrario, la ejecución de actos coactivos A (uso de la fuerza física) no lleva, de forma necesaria, a que los individuos actúen intencionalmente. A diferencia de la «coacción A», las sanciones no privan a los individuos de la posibilidad de negarse a actuar en contra. Existe, en definitiva, una elección de forma que los individuos podrían elegir rehusarse a actuar y sufrir las eventuales consecuencia negativas anunciadas en la sanción ${ }^{57}$. En efecto, si un policía sorprende a un individuo fumando, y por la fuerza apaga su cigarrillo, no puede decirse que el individuo dejó de fumar intencionalmente, a diferencia de lo ocurrido en el caso de María y Pedro, quienes intencionalmente decidieron no fumar.

La relación entre las sanciones y la coacción B es evidente. La coacción, en este caso, se refiere a la posibilidad de que los individuos autorizados impongan la consecuencia establecida en la sanción. Sin embargo, la existencia de sanciones y su funcionamiento en el razonamiento práctico, es independiente

56 En palabras de Lamond: «it is a mistake to think that all legal uses of physical force are sanctions, or that sanctions invariably involve the use of physical force. Physical force can be used to quarantine the sick or take the mentally ill into care, neither of which amount to sanctions... Equally, sanctions which take the form of withdrawing some ability, e.g. the eligibility for public office, or forfeiting intangible property such as bank accounts or intellectual property, do not require physical force» (LAMOND, G., «Coercion...», op. cit., p. 649).

57 Ibidem. 
de la coacción $\mathrm{B}$, es decir que las sanciones no dependen de que en cada caso de incumplimiento de las normas se apliquen actos coactivos. En efecto, es común que los actos coactivos, en relación con una conducta determinada, sean estadísticamente bajos, y aun así la coerción tenga capacidad suficiente para motivar la acción. En estas situaciones, lo importante para la capacidad motivadora de las sanciones jurídicas es que se genere en los individuos la creencia de que se impondrán las consecuencias establecidas en las sanciones jurídicas. Schauer menciona un caso que ejemplifica esta cuestión. Las agencias de impuestos llevan a cabo exhaustivas auditorías para revisar el pago de impuestos de un grupo reducido de contribuyentes, y persigue el pago efectivo de estos en un número aún menor de casos. Estas agencias desarrollan agresivas estrategias de publicidad para dar a conocer las auditorías y los casos de investigaciones penales por fraude tributario. Claramente, lo que pretenden las agencias es generar en los contribuyentes una creencia en la probabilidad de la ejecución de actos coactivos, pese a que, en realidad, el número de estos sea estadísticamente bajo ${ }^{58}$.

Lo importante a resaltar del caso mencionado por Schauer es que, a diferencia de la conexión existente entre las sanciones jurídicas y coerción, la relación entre sanciones y coacción (incluso la coacción tipo $\ll \mathrm{B} »$ ) es contingente y depende de cuestiones empíricas respecto a la aplicación efectiva de sanciones. Las sanciones relacionadas con las normas jurídicas generales son a su vez generales. La regla del ejemplo donde se prohíbe fumar, es general (regula todos los casos de fumar en sitios públicos); asimismo, la sanción establecida (multa y arresto) es general. Por el contrario, los actos coactivos son, por necesidad conceptual, particulares. En todos los casos en que los individuos fumen en los lugares prohibidos por la regla, resulta aplicable la sanción; pero solo en los casos en que, en efecto, los agentes competentes impongan la multa o arresten a los infractores, aparece el acto coactivo. No sobra agregar que no todo acto coactivo depende de la existencia de una sanción. Esto se evidencia en los casos de medidas cautelares o preventivas. Si a Juan lo detienen de forma preventiva en el marco de una investigación penal (siendo Juan inocente), no se puede afirmar que la detención (un acto coactivo) opere, en este caso, como la imposición de una consecuencia negativa ante la inobservancia de una exigencia normativa.

Queda por indagar la relación entre las sanciones jurídicas y la coacción C. Este tipo de coacción apunta a la idea de que los deberes jurídicos se caracterizan porque su incumplimiento puede ser exigido, por ejemplo, mediante un

58 SChauer, F., The Force of the Law..., op. cit., 8-10. 
mandato judicial, incluso por medio de la fuerza. Según esto, un deber jurídico se diferencia de los deberes morales, entre otras razones, porque existen instituciones y personas con el poder de exigir su cumplimiento. Sin pretender entrar a definir el alcance general de esta tesis, es posible diferenciar entre:

(a) La existencia de los deberes jurídicos,

(b) La posibilidad de hacer exigibles tales deberes jurídicos, y

(c) Las sanciones jurídicas.

Tanto (b) como (c) son formas o mecanismos para logar que los individuos cumplan con los deberes (a); sin embargo, (b) es posterior al incumplimiento de (a), además de restaurativo (es decir, su propósito es restaurar o hacer cumplir el deber). Así las cosas, la finalidad de (b) no es motivar a los individuos a que actúen conforme a los deberes jurídicos, sino asegurar (ex post facto), en los casos de incumplimiento, que se realice lo exigido por el deber jurídico. Por otra parte, (c) funciona, como ya se ha explicado, generando motivos para que los individuos actúen conforme a sus deberes. En ese sentido, (c), a diferencia de (b), es, por necesidad conceptual, previo a la acción, pues como se dijo, su propósito es motivar a realizar esta, y no reparar o restaurar el eventual incumplimiento de deberes. Por lo tanto, toda vez que las sanciones pueden existir con independencia de la eventual exigencia (incluso por la fuerza) de los deberes jurídicos, no existe una conexión necesaria entre las sanciones y la coacción C.

\section{Conclusiones}

Este trabajo finaliza con una breve recapitulación y algunas conclusiones. Las sanciones jurídicas son una técnica de motivación empleada por los sistemas jurídicos para que los individuos actúen conforme a las normas jurídicas. La coerción es el elemento central en el funcionamiento de las sanciones jurídicas, al entenderse como la presión que genera en la deliberación de los individuos la probabilidad de que las autoridades apliquen una sanción. Por ello, la función normativa de las sanciones depende de que la coerción se constituya en un motivo para actuar conforme al derecho (fuerza coercitiva del derecho). Las sanciones, por lo tanto, se constituyen en motivos para la acción una vez coercionan al individuo para que actúe conforme a las reglas.

La coerción se refiere a los motivos de los individuos generados por el temor de que se causen las acciones anunciadas en la sanción (negativa), y que por lo tanto, afectan su deliberación práctica acerca de cómo deben actuar o decidir. Lo fundamental en la explicación de las sanciones es como son capa- 
ces de motivar a los individuos por medio de la coerción, con independencia de que objetivamente la sanción genere una razón prudencial para actuar. No quiere decir, desde luego, que la coerción sea una consecuencia exclusiva de las sanciones. En efecto, la coerción puede surgir - por ejemplo- como consecuencia de diferentes tipos de amenazas que difícilmente pueden considerarse sanciones, por ejemplo, la amenaza de un ladrón.

Por último, se señaló que no existen conexiones necesarias entre las sanciones jurídicas y la coacción Por ello, es un error pretender explicar cómo funcionan las sanciones jurídicas a través de una teoría de la coacción en general o del uso de la fuerza en particular. Esta conclusión delimita la pregunta que ha preocupado constantemente a la filosofía del derecho sobre las relaciones entre la naturaleza normativa del derecho y las sanciones. Si la naturaleza de las sanciones no es coactiva, como se concluyó, entonces la pregunta sobre las relaciones entre derecho y sanciones jurídicas es independiente de la pregunta sobre las relaciones entre derecho y coacción (en cualquiera de sus tipos).

\section{LISTA DE REFERENCIAS}

AUDI, R., Reasons, practical reason, and practical reasoning, Ratio an International fournal of Analytic Philosophy 17 (2004), pp. 119-149. https://doi.org/10.1111/j.14679329.2004.00243.x

ANDERSON, S., «Coercion», Stanford Encyclopedia of Philosophy (2015), Edward N. Zalta (ed.), URL = https://plato.stanford.edu/archives/sum2015/entries/coercion/

— «Coercion as Enforcement, and the Social Organisation of Power Relations: Coercion in Specific Contexts of Social Power», Furisprudence, 7 (2016), pp. 525-539.https://doi.or $\mathrm{g} / 10.1080 / 20403313.2016 .1236892$

Austin, J., The province of jurisprudence determined, Cambridge University Press, Oxford, 1995.

Barreto-Moreno, A. A. y Pulido-Ortiz, F. E., «El carácter sancionatorio del régimen de inhabilidades e incompatibilidades», Revista furídicas, 16 (2018), pp. 153-171.https:// DOI: $10.17151 /$ jurid.2019.16.1.10

Bоввіо, N., El positivismo jurídico, Debate, Madrid, 1993.

Berman, M., The Normative Functions of Coercion Claims. Legal Theory 8 (2002), pp. $45-89$.

DWORKIN, R., Law's Empire, Harvard University Press, Cambridge, 1986.

FARrell, M., Entre el Derecho y la Moral, Abeledo Perrot, Buenos Aires.

FERrer, J., Las normas de competencia. Un aspecto de la dinámica jurídica, Centro de Estudios Políticos y Constitucionales Madrid, 2000.

FINNIS, J., Natural law and natural rights, 2. ${ }^{\mathrm{a}}$ ed., Oxford University Press, Oxford, 2011.

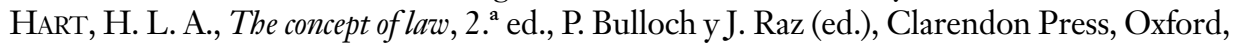
1994. 
Himma, K., «The Authorisation of Coercive Enforcement Mechanisms as a Conceptually Necessary Feature of Law», Furisprudence, 7 (2016), pp. 593-626. https://doi.org/10.108 0/20403313.2016.1236896

Holmes, O.W., «The Path of the Law», Harvard Law Review, 10 (1897), pp. 457-478.

KANT, I., Fundamentación para una metafísica de las costumbres, versión castellana y estudio preliminar por Roberto R. Aramayo, 2. ${ }^{a}$ ed., Alianza Editorial, Madrid, 2012,

Kelsen, H., «The Law as a Specific Social Technique», University of Chicago Law Review, 9 (1941), pp. 75-97

Kelsen, General Theory of Law and State, Harvard University Press, Cambridge Massachusetts, 1945.

Kelsen, H., Teoría Pura del Derecho, trad. R. Vernengo, 14a. ed., Porrúa, México, 2005.

LAMOND, G, «The Coerciveness of Law», Oxford Fournal of Legal Studies, 20 (2000) pp. 3962. https://doi.org/10.1093/ojls/20.1.39

LamOND, G., Coercion and the Nature of Law, Legal Theory, 7 (2001), pp. 35-57. https:// doi.org/10.1017/S1352325201071026

LAMOND, G., «Coercion», en A Companion to Philosophy of Law and Legal Theory, Dennis Patterson (ed.), Wiley-Blackwell, Oxford, 2010, 642-653.

Massini-Correas, C., «The Force of Law», Persona y Derecho, 78 (2018), pp. 350-352. https://revistas.unav.edu/index.php/persona-y-derecho/article/view/11599

Nino, C., La validez del Derecho, Astrea, Buenos Aires, 1985.

Nozick, R., Coercion, Philosophy, Science, and Method: Essays in Honor of Ernest Nagel, Sidney Morgenbesser, Patrick Suppes y Morton White (eds.), St. Martin's Press, New York, 1969, pp. 440-472.

OBERDIEK, H., «The Role of Sanctions and Coercion in Understanding Law and Legal Systems», American fournal of Furisprudence 21 (1976), pp. 71-94. https://scholarship.law. nd.edu/ajj/vol21/iss1/4

RAz, J., The Concept of a Legal System: An Introduction to the Theory of a Legal System, Clarendon Press, Oxford.

- Practical Reason and Norms, Oxford University Press, Oxford, 1990.

RiCHARDSON, H., «Moral Reasoning», The Stanford Encyclopedia of Philosophy (Winter 2014 Edition), Edward N. Zalta (ed.), URL = https://plato.stanford.edu/archives/win2014/ entries/reasoning-moral/

Schauer, F., The Force of the Law, Harvard University Press, Cambridge, 2015.

Sмітн, M., Valuing: desiring or believing. Reduction, Explanation and Realism, D. Charles y K. Lennon (eds.), Oxford University Press, Oxford, 323-360.

Stavropoulos, N., «The Relevance of Coercion: Some Preliminaries», Ratio furis 22(2009), pp. 339-358. https://doi.org/10.1111/j.1467-9337.2009.00429.x

VON Wright, Norm and Action. A Logical Inquiry, Routledge \& Kegan Paul, London, 1963

YANKAH, E., «The Force of Law: The Role of Coercion in Legal Norms», University of Richmond Law Review, 42 (2008), pp. 1195-1256. https://scholarship.richmond.edu/cgi/ viewcontent.cgi? article $=2750 \&$ context=lawreview

ZAMBRANO, P., «El derecho como razón excluyente para la acción: una aproximación desde la teoría iusnaturalista del derecho de John Finnis, Problema», Anuario de Filosofía y Teoría del Derecho, 4 (2010), pp. 323-366. http://dx.doi.org/10.22201/iij.24487937e.2010.4.8097 
0000 